\title{
A New Method for Valuing Treasury Bond Futures Options
}

The Research Foundation of The Institute of Chartered Financial Analysts 


\section{Research Foundation Publications}

Canadian Stocks, Bonds, Bills, and Inflation: 1950-1987

by James E. Hatch and Robert E. White

Closed-Form Duration Measures and Strategy Applications

by Nelson J. Lacey and Sanjay K. Nawalkha

Corporate Bond Rating Drift: An Examination of Credit Quality Rating Changes Over Time

by Edward I. Altman and Duen Li Kao

Default Risk, Mortality Rates, and the Performance of Corporate Bonds

by Edward I. Altman

Durations of Nondefault-Free Securities

by Gerald O. Bierwag and George G. Kaufman

Earnings Forecasts and Share Price Reversals

by Werner F.M. De Bondt

The Effect of Illiquidity on Bond Price Data: Some Symptoms and Remedies by Oded Sarig and Arthur Warga

Ethics in the Investment Profession: A Survey

by $\mathrm{E}$. Theodore Veit, CFA, and Michael R. Murphy, CFA

The Founders of Modern Finance: Their Prize-winning Concepts and 1990 Nobel Lectures
Initial Public Offerings: The Role of Venture Capitalists

by Joseph T. Lin and Anthony Saunders

A New Perspective on Asset Allocation by Martin L. Leibowitz

The Poison Pill Anti-takeover Defense: The Price of Strategic Deterrence

by Robert F. Bruner

Program Trading and Systematic Risk by A.J. Senchack, Jr., and John D. Martin

The Role of Risk Tolerance in the Asset Allocation Process: A New Perspective by W.V. Harlow III, CFA, and Keith C. Brown, CFA

Selecting Superior Securities by Marc R. Reinganum

Stock Market Structure, Volatility, and Volume

by Hans R. Stoll and Robert E. Whaley

Stocks, Bonds, Bills, and Inflation:

Historical Returns (1926-1987)

by Roger G. Ibbotson and Rex A.

Sinquefield

(Published with Business One Irwin) 


\section{A New Method for Valuing Treasury Bond Futures Options}


(C) 1992 The Research Foundation of the Institute of Chartered Financial Analysts.

All rights reserved. No part of this publication may be reproduced, stored in a retrieval system, or transmitted, in any form or by any means, electronic, mechanical, photocopying, recording, or otherwise, without the prior written permission of the copyright holder.

This publication is designed to provide accurate and authoritative information in regard to the subject matter covered. It is sold with the understanding that the publisher is not engaged in rendering legal, accounting, or other professional service. If legal advice or other expert assistance is required, the services of a competent professional should be sought.

From a Declaration of Principles jointly adopted by a Committee of the American Bar Association and a Committee of Publishers.

ISBN 10-digit: 0-943205-15-8 ISBN 13-digit: 978-0-943205-15-1

Printed in the United States of America

June 1992 


\section{Mission}

The mission of the Research Foundation is to identify, fund, and publish research material that:

- expands the body of relevant and useful knowledge available to practitioners;

- assists practitioners in understanding and applying this knowledge; and

- enhances the investment management community's effectiveness in serving clients.

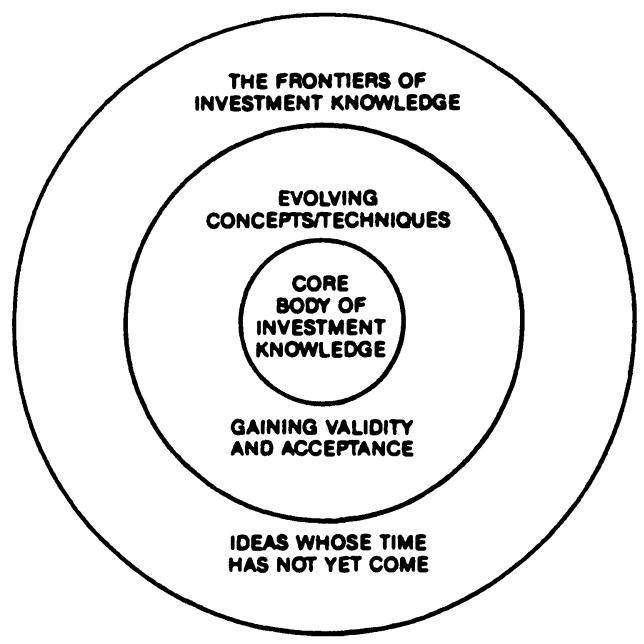

The Research Foundation of

The Institute of Chartered Financial Analysts

P. O. Box 3668

Charlottesville, Virginia 22903

Telephone: 804/977-6600

Fax: 804/977-1103 


\section{Table of Contents}

Acknowledgments.$\ldots \ldots \ldots \ldots \ldots \ldots \ldots \ldots \ldots$ viii

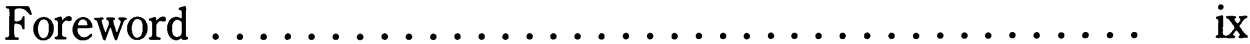

Chapter 1. Introduction $\ldots \ldots \ldots \ldots \ldots \ldots \ldots \ldots, 1$

Chapter 2. Arbitrage-Free Option Pricing .......... 3

Chapter 3. The Trinomial Model of Interest Rates .... 7

Chapter 4. Applications of the Trinomial Model....... 11

Chapter 5. Empirical Tests.................. 15

Chapter 6. Summary.................. 21 


\section{Acknowledgments}

The authors acknowledge the helpful comments and suggestions of Thierry Bollier, Michael Brennan, George Constantinides, Ken Dunn, Dan French, Alan Hess, John Martin, and Suresh Sundaresan. Yongjai Shin provided valuable computational assistance. The authors are solely responsible for any errors contained herein. We gratefully acknowledge financial support from the University of Texas at Austin College and Graduate School of Business, the Research Foundation of the Institute of Chartered Financial Analysts, and the Institute for Quantitative Research in Finance. We also thank the Chicago Board of Trade for providing data in support of this project.

Ehud I. Ronn

Debt Markets Group

Merrill Lynch \& Company

and

College and Graduate School of Business

University of Texas at Austin

Robert R. Bliss, Jr.

School of Business

Indiana University 


\section{Foreword}

This research by Ronn and Bliss melds an old idea with a new analytical method. The old idea is familiar to most of us: Buy or sell decisions are based on whether expected value is greater than, less than, or equal to current price. The new analytical method is an arbitrage-based model in which the value of every financial asset depends upon some other underlying asset.

Say we wish to price the put or call options on Treasury bond futures contracts. Three asset values are involved: the futures, the underlying asset of the futures (that is, the Treasury bonds), and a put or call on the futures. The value of the Treasury bonds depends on interest rates, which depend on the economy's real productivity and inflation. The value of the futures contracts depends on the value of the bonds. The value of the options depends on the value of the futures contract. Yet, the values of the futures contract and options depend on time to maturity-that is, interest opportunity costs-and the volatility of each asset. Moreover, a decay function is present on the futures contracts and options that is absent in the bonds. When the former expire, their value is zero. When bonds mature or are called, one receives the face value or call price.

To unscramble this conundrum and yet be true to the nature of scientific inquiry, a model is needed that explains the triad of relations. Ronn and Bliss begin with the standard binomial option pricing model. Binomial means two possible outcomes, say an upward or downward move in interest rates. In an arbitrage-free world, investors prefer more wealth to less and tend to arbitrage away excess profit opportunities.

Binomial models are poor predictors of interest rates because they allow only up and down moves. Ronn and Bliss's trinomial model adds the realistic possibility of no or very little change. The authors remind us that in an arbitrage-free world, the price of a call option with known market and strike prices but an unknown future price may be estimated by forming a portfolio of stocks and bonds that has the same payoff as the call. This replicating portfolio has the intriguing characteristic of eliminating probabilities in the equation of price determination. The up moves of the call offset the down moves of the portfolio, and vice versa. This fundamental conclusion allows the authors to investigate the pricing mechanism without the need to assign probabilities to any of the three interest rate moves. 
Once the model was formulated, it was applied to Treasury bond futures and related option contracts. The authors tested the model using four variables: a short-term interest rate, the slope of the term structure, the curvature of the term structure, and the latest one-month change of the short-term rate.

Using zero-coupon bond prices implied by estimates of the pure discount term structure, these four variables were calculated in one period and then used to estimate the term structure in future periods conditional on which particular state of the world materialized. The authors then tested these projected values after classifying realized term structure moves as up, down, or no change. The overall test results showed that the fitted prices explained 66.5 percent of actual, next-period variation of pure discount bond prices.

Another set of data was used to conduct out-of-sample tests. Recall that out-of-sample tests are necessary to validate a model. Out-of-sample tests help to determine whether a model is biased. If it is unbiased, it may be used either to forecast or to formulate a trading rule. The authors computed, in order, the forecasted conditional process of all deliverable bonds for each period, the value of the futures contract, and the value of the options, based on forecasted value of the futures contract.

Tests of bias in the value of futures favored the hypothesis of no bias. A similar test of options found a downward bias because the model tends to underestimate interest rate volatility. Overall, the results tend to support the model. The analysis and the test suggest that the model may be used to hedge the risk of any contingent asset that is sensitive to interest rate risk.

Few have tried to do what Ronn and Bliss have succeeded in doing. To model three assets and their pricing at one time is no mean feat when the assets are assumed to be free of arbitrage and the term structure of interest rate shifts from one state to the next. That difficulty alone makes their contribution significant. Yet they are able to take this analysis the next step-that is, to predict with high reliability the prices of Treasury bond futures and the options on those futures.

The emerging trading rules are straightforward: If opportunities to earn excess returns exist (i.e., when prices deviate from their estimated intrinsic values), the use of calls and the hedge portfolio will do it. For example, if price exceeds the estimated option value, the best move is to short the call, buy the replicating portfolio, and invest the difference in a risk-free security. If price is less than the estimated value indicated by the model, buy the call and short the hedge portfolio. The authors suggest that those economic agents whose trading costs are minimal are likely to be able to invoke this strategy and earn excess returns.

This model is an important step in estimating Treasury bond options (or 
futures or term structure). For traders, the model shows the conditions under which arbitrage opportunities are likely to exist. It also tells them that minimal trading costs are necessary to exploit these opportunities.

That the model predicts arbitrage opportunities that are not exploitable unless trading costs are low is a priori unsurprising. If this market is nearly as efficient as lore says it is, the results are not startling. The amazing thing, as lore continues to tell us, is that those who run trading desks continue to try to reap excess returns in the face of the formidable odds against doing so. The task is to measure total trading costs-not only in-and-out commissions but also such costs as bookkeeping, monitoring, and administration. Best execution alone does not do it. Indeed, the anecdotal evidence suggests that trading desks try to exploit arbitrage profits from efficient markets. This study implies that when total costs are imputed to a trade, the trade is not likely to be worth the try.

On the equity analysis level, if variable discount rates are used in two- or three-phase dividend discount models, this term structure model provides better clues about the correct set of rates to use.

The study has some inferential policy implications. For example, does one regulate one market in isolation from related markets-say, the options market apart from the futures markets, given that the contingent claims are highly related? If market volatility is an issue, which market should be regulated? Are Treasury funding or refunding operations dependent on interest rate forecasts? If monetary policy drives interest rates, might not a model such as this help forecast the term structure?

Despite the difficulty and complexity of the problem they tackled, Ronn and Bliss were not found wanting. They demonstrate once again that rigorous theory, properly applied, results in usable notions for even the most mundane of applications. The Research Foundation thanks them for their contribution.

Charles A. D'Ambrosio, CFA

Research Director

The Research Foundation of

The Institute of Chartered Financial Analysts 


\section{Introduction}

Arbitrage-based models have been a particularly appealing form of analysis in financial economics, relying as they do on a parsimonious set of assumptions. These arbitrage models have typically been applied to the valuation of equities and their derivative products. More-recent work has focused on the use of such arbitrage-based models for the valuation of fixed-income securities and their derivative instruments.

In this study, we derived the properties of a nonstationary trinomial model of intertemporal changes in the term structure of interest rates and applied our model to the pricing of Treasury bond futures contracts and their options. ${ }^{1}$ The importance of such an endeavor lies in the explanation and rationalization of the prices on the world's most popular futures contract (in volume of trade) and the call and put options written on these contracts. After accounting for the timing and quality delivery options in the futures contracts, we tested the model values against the market prices of the Treasury bond futures and the related options contracts. This test is an appropriate out-of-sample test of the model's validity because the market prices of the Treasury bond futures and their options were not used in estimating the model's parameters. We performed two types of empirical tests. The first set examined whether the model's values for futures and options are unbiased estimates of the market prices. The second set considered a trading rule based on the discrepancy between the options model's values and their corresponding market prices. Because the data support the model, it may be used to hedge the risk of any interest-rate-contingent security.

\footnotetext{
${ }^{1} \mathrm{~A}$ rigorous technical exposition of the material presented in this monograph appears in two related papers by the authors: "Arbitrage-Based Estimation of Non-Stationary Shifts in the Term Structure of Interest Rates," Journal of Finance 44 (July 1989), pp. 591-610, and the working paper, "A Non-Stationary Trinomial Model for the Valuation of Options on Treasury Bond Futures Contracts." Both papers are available from the authors.
} 



\section{Arbitrage-Free Option Pricing}

Before describing the model we have developed, it is useful to discuss a simple model of option pricing, the Cox-Rubinstein model. ${ }^{2}$ This illustrates the approach we used and develops some important relationships.

\section{A Binomial Model for Pricing Stock Options}

Suppose we have two assets whose prices are given, a stock and a riskless bond, and we are interested in pricing a call on the stock. We know the stock is worth $S$ today and assume that next period it will either increase to $u S$ if things go well (the $U p$ state occurs) or decrease to $d S$ if things go poorly (the Down state occurs). Suppose that the chance of an $U p$ state is $q$ and the chance of a Down state is $(1-q)$; we do not need to know these probabilities so labeling them does no harm. The stock's price today and its possible value next period can be represented graphically as follows:

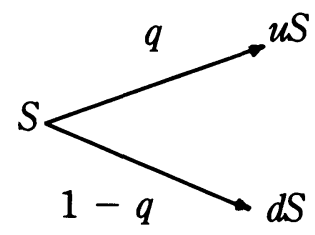

The second asset is a riskless bond. Its price today is $\$ 1$, and it pays off $r$ regardless of which state occurs next period. The quantity $r$ is 1 plus the riskless rate of interest. A condition for no arbitrage is that $d \leq r \leq u$.

\footnotetext{
${ }^{2}$ The following discussion is taken from Options Markets, by John C. Cox and Mark E.
} Rubinstein (Englewood Cliffs, N.J.: Prentice Hall, Inc., 1985). 
One of the fundamental concepts in modern finance is that riskless profits cannot occur for very long. This conclusion does not require any assumptions about risk preferences (e.g., that investors are risk averse), only the assumption that investors prefer to have more wealth to less, all other things being equal. If riskless or "arbitrage" profits appear possible, investors will quickly cause the prices of the underlying assets to change as they trade to take advantage of this opportunity.

Armed with the no-arbitrage argument, we wish to price a call on a share of the stock. Assume the call has an equilibrium price today of $C$, which is what we wish to discover, and a strike price of $K$, which we know. We wish to form a portfolio of stocks and bonds that has the same payoff as the call next period, irrespective of which state occurs; hence, the portfolio is called a "replicating" portfolio. Because the cash flows of the portfolio next period are exactly the same as the call's, the price of the portfolio this period must equal the price of the call. If this were not so, we could short the higher priced of the two and buy the lower priced. The profit would be the difference in the prices today, and next period, the cash outflows from the shorted asset would be exactly offset by the cash inflows of the asset purchased.

If the $U p$ state occurs, the call will pay off $\max \{0, u S-K\}$, and if a Down state occurs, it will pay off $\max \{0, d S-K\}$ :

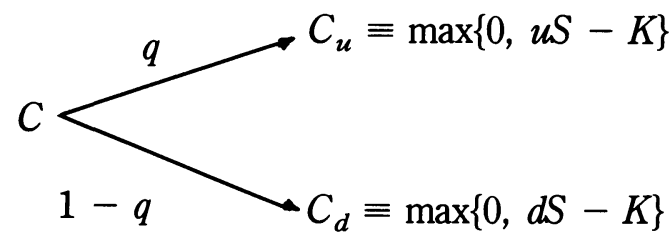

Now, form a portfolio of $\Delta$ shares of stock and $B$ riskless bonds, and set $\Delta$ and $B$ so that the portfolio has the same payoffs as the call. ${ }^{3}$ That is,

$$
\begin{aligned}
& \Delta(u S)+B r=C_{u}, \text { and } \\
& \Delta(d S)+B r=C_{d} .
\end{aligned}
$$

Because $u, d, S, r, B$, and $K$ are known, we can compute $C_{u}$ and $C_{d}$ and plug these in to solve for $\Delta$ and $B$ (there are two equations in two unknowns). By the

\footnotetext{
${ }^{3} \Delta$ is called the "hedge ratio" and is useful in actually constructing hedge portfolios using options.
} 
"no arbitrage" argument, the price of the portfolio today, $\Delta S+B$, must equal the price of the call, $C$. Substituting the values of $\Delta$ and $B$, we obtain:

$$
C=\Delta S+B=\left[\left(\frac{r-d}{u-d}\right) C_{u}+\left(\frac{u-r}{u-d}\right) C_{d}\right] / r .
$$

Notice that $q$ does not appear in the equation for the price of the call. This is one of the key results of options pricing; because we can replicate the call's payoff for each state next period, we do not care about the probabilities of the respective states. If we define $p \equiv(r-d) /(u-d)$, we get $1-p=(u-r) /(u$ $-d$ ), and then $C$ can be expressed as:

$$
C=\frac{p C_{u}+(1-p) C_{d}}{r} .
$$

Because $p$ is between 0 and 1 (because $u>r>d$ ), we can think of $p$ as a probability. This is a risk-neutral probability for reasons that will be made clear shortly. With risk neutrality, the price of an asset today is the present value of the expected payoff next period. The expected payoff is the sum of the payoff in each state weighted by the risk-neutral probability of that state occurring. That is,

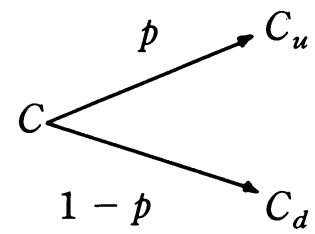

It is important to emphasize that risk-neutral probabilities are not the objective probabilities of the $U p$ and Down states, $q$ and $1-q$. They are only convenient shorthand for the relationships among $u, d$, and $r$ that permit us to price the call as if $p$ and $1-p$ were the true probabilities and as if investors were risk neutral.

This is a very powerful result. Pricing assets can be a complex undertaking, involving strong assumptions about investors' risk preferences or about the distributions of returns including probabilities of outcomes. If we can form replicating portfolios, however, as we did in pricing the call, we can cut through that complexity and price the replicated asset as if investors were risk neutral (without bothering about whether they actually are) and as if the objective probabilities were the risk-neutral probabilities (without worrying about whether that is true). 
The important question is whether a model's approximation of reality is "good enough." For pricing models, this means:

- Do the prices predicted by the model reflect those observed in the market? If they do, the model can be used to price new assets (e.g., a call with a different exercise price).

- If the model's prices differ from the observed prices, can we make money trading on the differences? That is, can the model help identify market inefficiencies? 


\section{The Trinomial Model of Interest Rates}

The model we developed (and tested) describes the pricing of call and put options on Treasury bond futures contracts. The underlying asset for the option is the futures contract, for which the underlying asset is a U.S. Treasury bond. The price of the Treasury bond in turn depends on interest rates. We start with basic principles and build up to the futures prices through the valuation of Treasury bonds. This captures the wealth of detail that must be considered in practice: cheapest-to-deliver options, delivery timing, no-arbitrage relations between the futures contracts and Treasury bonds, and so forth.

\section{The Trinomial Interest Rate Model}

The stock option example in the previous section assumed that the stock price can take on one of two values next period. In this model, the entire term structure next period can take on one of three values: $U p$, No Change, and Down. ${ }^{4}$ The initial attempt at modeling movements of the entire term structure used a simple constant parameter binomial (two possible states next period) model. ${ }^{5}$ This did not work very well in practice. A trinomial (three possible states next period) model works much better, not just because three states is a better approximation of reality than two-which will always be true-but because the third state (No Change) captures an important characteristic of the real world. Often interest rates do not change very much from one month to the

\footnotetext{
${ }^{4}$ The term No Change does not imply that the term structure is literally unchanged; rather, it implies relatively "minor" changes from one month to the next.

${ }^{5}$ See T.S.Y. Ho and S. Lee, "Term Structure Movements and Pricing Interest Rate Contingent Claims," Journal of Finance 41 (December 1986):1011-29.
} 
next. The binomial model says that interest rates must always change significantly from one month to the next.

In the Cox-Rubinstein stock option model, the price of the stock, $S$, is "perturbed" each period by either $u$ or $d$. In modeling changes in the entire term structure, we focused on modeling changes in the prices of zero-coupon, or pure discount, bonds. Note that the stock example was based on only one underlying security. In the present case, we examined the changes in the prices of the entire array of zero-coupon bonds that define the term structure of interest rates.

The benchmark for next period's price of the bond is not the current price of the bond. For example, today's 24 -month bond will be a 23-month bond next month, and through time, the price of zero-coupon bonds must approach par as maturity decreases. Embedded in the current term structure is an estimate of the price, one month from now, of a 23 -month bond. This is the "forward price," or the ratio of today's prices of the 24 -month bond to the 1-month bill. The 1-month-ahead 23-month forward price is the price of a 23-month investment (to begin 1 month from now) that can be "locked in," or secured, today by buying a 24 -month bond financed by borrowing at the 1-month rate of interest. The forward price, which can be observed today, is therefore the benchmark to which the perturbations are applied to arrive at next period's state-dependent ( $U p$, No Change, Down) prices for the 23-month bond.

Furthermore, although changes in the prices of bonds of different maturities are related, they are not identical. Long-term zero-coupon bond prices fluctuate more than short-term ones. Each maturity, therefore, has a different set of potential perturbations. We assumed, however, that the state actually realized next period, $U p$, No Change, or Down, is the same for all maturities. ${ }^{6}$

Mathematically, if $h^{u}(m), h^{n}(m)$, and $h^{d}(m)$ are the perturbations appropriate to an $(m+1)$-period bond (as measured today) in states Up, No Change, and Down, then the three possible next-period prices of an $m$-period bond are:

$$
\begin{aligned}
& P^{u}(m)=\frac{P(m+1)}{P(1)} h^{u}(m), \\
& P^{n}(m)=\frac{P(m+1)}{P(1)} h^{n}(m),
\end{aligned}
$$

\footnotetext{
${ }^{6}$ This prohibits short rates moving down at the same time that long rates move up--admittedly a simplification of what may actually occur in the real world.
} 


$$
P^{d}(m)=\frac{P(m+1)}{P(1)} h^{d}(m),
$$

where $P(m+1), P(1)$, and the $h^{s}($.$) are all known today. Only the actual state,$ $s \in\{u, n, d\}$, which will be realized next period, is unknown.

Empirically, the volatility of interest rates is affected by their current levels: Higher interest rates are associated with higher levels of volatility. We modeled the time variation in the potential $U p$, No Change, and Down movements as functions of four variables calculated from the current term structure: the short-term interest rate, the slope of the term structure, the curvature of the term structure, and the latest one-month change in the short-term rate. We used linear regressions to estimate the relationship between these variables and the magnitude of the potential changes.

Because these four variables can be calculated from the term structure, we can project the state-dependent term structure next period, compute the values of the four variables next period (for each possible state), and then use these to project the possible term structures in the subsequent period. This process can be repeated indefinitely, although in practice we only projected out two periods. Replicating portfolio arguments similar to those used in the Cox-Rubinstein model show that the perturbations $\mathrm{h}^{\mathrm{s}}($.$) all satisfy$

$$
h^{u}(m) \pi^{u}+h^{n}(m) \pi^{n}+h^{d}(m) \pi^{d}=1
$$

for all $m$, and the $\pi \mathrm{s}$ have the following properties:

$$
\begin{aligned}
& \pi^{u}+\pi^{n}+\pi^{d}=1, \text { and } \\
& 0 \leq \pi^{u}, \pi^{n}, \pi^{d} \leq 1 .
\end{aligned}
$$

These $\pi$ s have the properties of probabilities, even though they have no necessary relation to the actual probabilities of the states being realized: The $\pi \mathrm{s}$ are the risk-neutral probabilities of the states.

It is important to note that the probabilities are identical for all maturities of the term structure.

\section{Example of a Two-Period Price Matrix}

As an example of the process of projecting future-state-contingent prices along the trinomial tree, consider the 24-month zero-coupon bond observed on December 30, 1988. It has a current price of $\$ 83.615$. On January 31,1989 , the bond will then have 23 months to maturity. If at that time a No Change state is realized, the price of the 23-month bond will be $\$ 83.926$. On the other hand, if a Down state ( $U p$ state) occurs, the price will be $\$ 83.027$ (\$86.377). The 
following month, on February 28, the then 22-month bond's price will depend on the states realized on January 31 and subsequently on February 28. For instance, if a No Change on January 31 is followed by an $U p$ on February 28 , the 22 -month bond price will be $\$ 86.031$. That is,

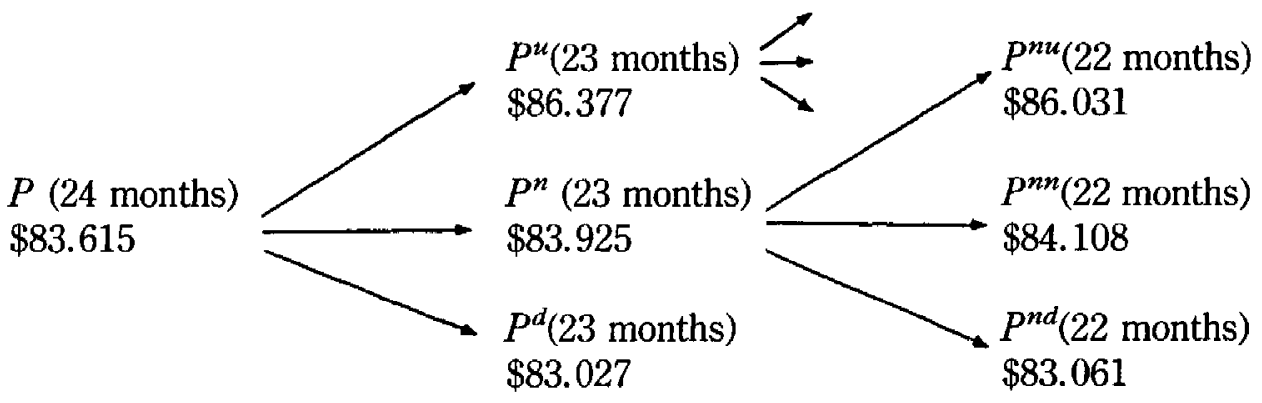




\section{Applications of the Trinomial Model}

The trinomial model permits us to project forward the possible state-dependent prices of bonds and provides the risk-neutral probabilities associated with these prices. This information can now be used to price securities whose payoffs depend on the future term structure; for instance, the call option on callable bonds or the mortgage prepaying option. In this monograph, we apply the trinomial model to price options on Treasury bond futures.

\section{Options on Treasury Bond Futures Contracts}

The U.S. Treasury bond futures contract traded on the Chicago Board of Trade matures four times a year, with the corresponding options maturing in the third week of the month preceding the Treasury bond futures delivery month. ${ }^{7}$ As an example, consider the valuation on July 31 of a Treasury bond futures option contract maturing three weeks later, on August 22, where the underlying futures contract delivery month is September. Figure 1 lays out the sequence of these events. The July 31 value of the option contract will depend on the current and projected values of the futures contract. Therefore, to determine the fair value of the option, we must first determine the value of the futures contract. The price of the futures contract on July 31 and at subsequent dates depends on the prices of the bonds that may be delivered to satisfy the contract.

The value of the futures contract on July 31 depends on the prices of the contract at two future dates: the beginning and end of the delivery month,

\footnotetext{
${ }^{7}$ In accordance with the specification of the Chicago Board of Trade, "options stop trading . . . on the last Friday preceding, by at least five business days, the first notice day for the corresponding T-bond futures contract."
} 


\section{FIGURE 1. Sequence of Events for Option Valuation}

Date Comments

July $31\left(t_{0}\right)$

August $22\left(t_{1}\right)$

September $1\left(t_{2}\right)$

September $30\left(t_{3}\right)$
Date of option valuation

Option expires; three possible states of nature, $\{u, n, d\}$ First date for delivery against futures contract; same three states of nature as on August $22\{u, n, d\}$

Second (and final) date for delivery against futures contract. Each state of nature at time September 1 has spawned three possible states of nature, for a total of nine states: $\{u u, u n, u d\},\{n u, n n, n d\},\{d u, d n, d d\}$.

September 1 and September 30. Although futures can be delivered against any time during the month, most contracts are closed out, or delivered against, either at the beginning or at the end of the delivery month.

Our procedure was to project the possible term structures of interest rates in each of the three possible states on September 1 and in each of the nine possible states on September 30. Using these state-contingent term structures, we computed the prices of all deliverable bonds in each state. Applying the Chicago Board of Trade's appropriate conversion factor, we identified the cheapest-to-deliver bond at each point; only the cheapest-to-deliver bonds are relevant to pricing the futures contract.

We derived the value of the futures contract by working backwards in time-that is, by determining the nine possible values of the futures contract on September 30, the three possible values on September 1, and then the single value on July 31. On September 30, when the futures contract is about to expire, the price of the contract is the adjusted price of the cheapest-to-deliver bond. ${ }^{8}$

At the beginning of the delivery month, September 1, we have two choices if we hold a short position in the futures contract. We can hold the contract one more period until September 30. In this case, the value of the futures contract is the $\pi$-weighted sum of the next-period state-dependent values of the futures contract. ${ }^{9}$ On September 1, we can also deliver against the contract immediately using the current, September 1, cheapest-to-deliver bond. Therefore, the

\footnotetext{
${ }^{8}$ The adjustment requires this calculation: bond price - accrued interest/conversion factor.

${ }^{9}$ Because the futures contract involves no current investment, we do not discount the end-of-period values before $\pi$-weighting them.
} 
September 1 futures price will be determined by the cheaper of the two strategies for fulfilling the contract. The value of the futures contract on July 31 is then simply the $\pi$-weighted average of the September 1 futures values. ${ }^{10}$

\section{Option Valuation}

To value the option on July 31, we first valued the option at its expiration. We assumed that the futures price relevant on August 22 for valuation of the options contract on that date is the state-dependent futures price that will occur on September 1.

It follows from the definition of the call option that the value at expiration is:

$$
C_{1}^{s}=\max \left\{0, F_{1}^{s}-K\right\} \text {. }
$$

The value of the option today, July 31 , is determined by three conditions:

1. The value of the option cannot be negative:

$C_{0} \geq 0$.

2. The option must be worth at least as much as its immediate exercise value: $C_{0} \geq F_{0}^{s}-K$.

3. The option must be worth at least as much as its replicating portfolio's value, as given by the three values at expiration weighted by the risk-neutral probabilities of those state-contingent payoffs and then discounted back to July 31 :

$C_{0} \geq P_{0}(3 \mathrm{wk})\left(\pi^{u} C_{1}^{u}+\pi^{n} C_{1}^{n}+\pi^{d} C_{1}^{d}\right)$,

where $\mathrm{P}_{0}(3 \mathrm{wk})$ is today's price of a three-week Treasury bill.

The valuations of the put option today and at expiration are similar.

\footnotetext{
${ }^{10} \mathrm{We}$ also carefully examined the alternative arbitrage strategies of buy on July 31-hold and deliver on September 1 or September 30.
} 



\section{Empirical Tests}

The first step in estimating and testing the model was to classify actual changes in the term structure into Up, No Change, and Down. The changes were first classified on the basis of the direction and magnitude of the observed change in the prices of various maturity bonds. The initial classifications were then fine-tuned to adjust for the fact that the model is a time-varying one.

\section{Tests of the Term Structure Model}

Preliminary regressions were run to compute the initial estimates of the relation between the observed perturbations and the four predictor variables. The $R^{2} \mathrm{~s}$ from these regressions are shown in Figure 2. Across individual maturities, the $R^{2}$ s range from 12 percent to 65 percent for the $U p$ state, from 23 percent to 58 percent for the Down state, and from 57 percent to 84 percent for the No Change state. In total, the fitted perturbations predict 66.5 percent of the actual variation in next-period bond prices from their currently observable forward prices.

The preliminary estimates of the state-contingent perturbations were then adjusted to impose the cross-sectional constraint and ensure that the $\pi \mathrm{s}$ are non-negative and sum to unity. The time series of resulting probabilities for the subperiod November 1985 through November 1988 is shown in Figure 3. For most months in the overall sample period, October 1979 through November 1988 , all three $\pi \mathrm{s}$ were positive.

\section{Tests of Futures Valuation}

We examined the model's lack of bias in the valuation of futures contracts. Define $f_{0}$ and $f_{2}$ as the futures contracts' observed market prices at times $t_{0}$ and $t_{2}$, respectively, and consider the regression equations: 


\section{FIGURE 2. $R^{2}$ of Trinomial Regressions}

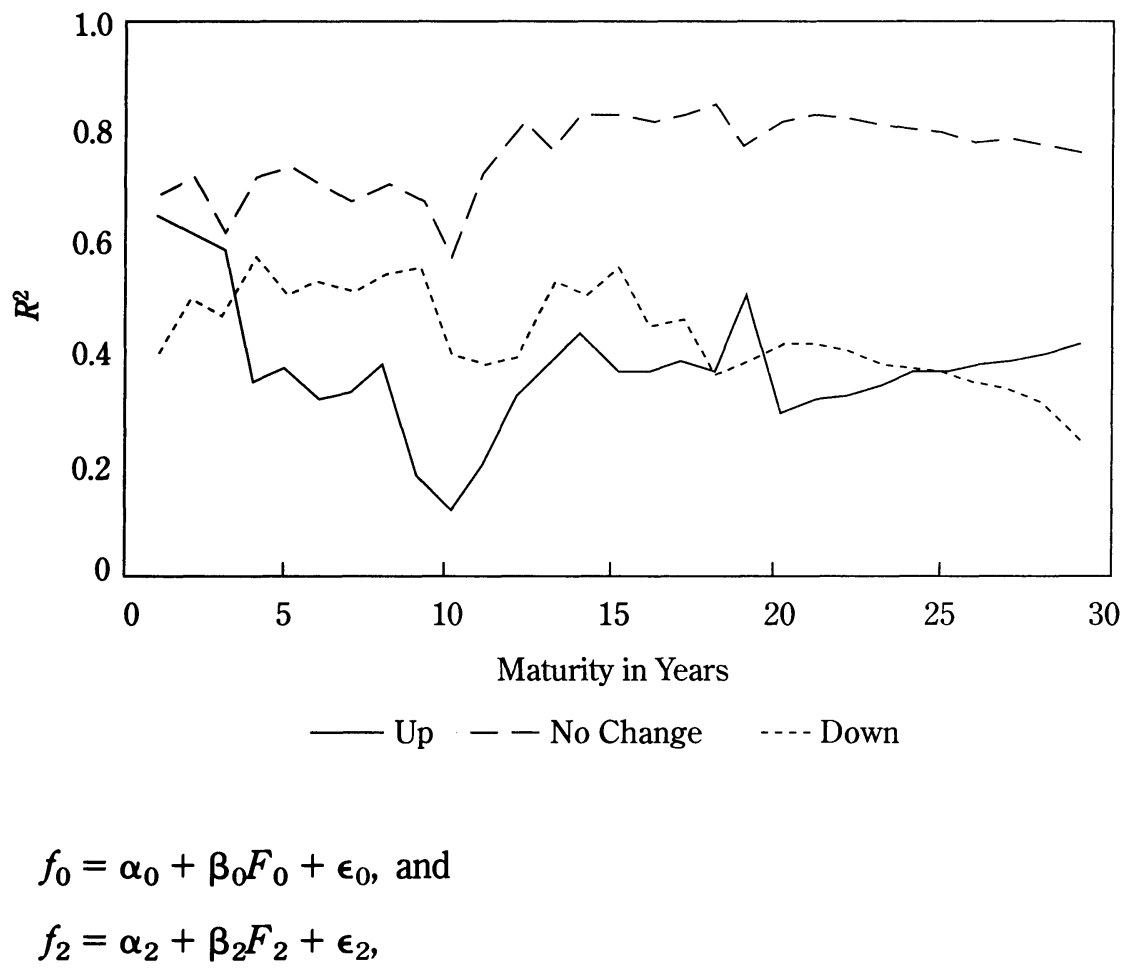

where $F_{0}$ and $F_{2}$ are the model-predicted values of the futures contract. Unbiasedness implies $\alpha_{0}=\alpha_{2}=0$ and $\beta_{0}=\beta_{2}=1$. These conditions are examined in Table 1.

TABLE 1. Analysis of Futures Contracts (number of observations $=25$ )

\begin{tabular}{ccc}
\hline Parameter & $f_{0}=\alpha_{0}+\beta_{0} F_{0}+\epsilon_{0}$ & $f_{2}=\alpha_{2}+\beta_{2} F_{2}+\epsilon_{2}$ \\
\hline \multirow{\alpha}{\alpha}{} & 1.360 & 0.9685 \\
$\hat{\boldsymbol{\beta}}$ & $(3.323)$ & $(1.201)$ \\
& 0.9835 & 0.9902 \\
$R^{2}$ & $(-3.337)$ & $(-1.008)$ \\
& 0.999 & 0.998
\end{tabular}

Note: Numbers in parenthesis are $t$-statistics. For $\beta$, the $t$-statistic is for $H_{0}: \beta=1$. 


\section{FIGURE 3. Estimates of Trinomial Probabilities, 1985-1988}

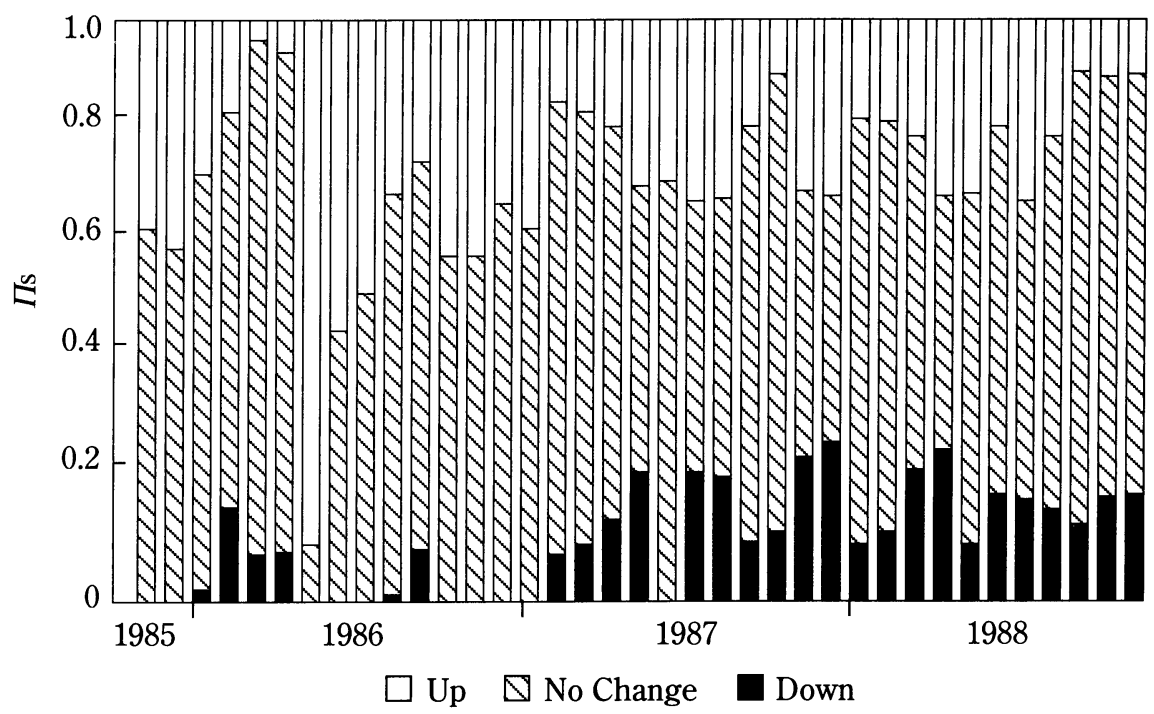

The results demonstrate that, at least insofar as the futures contract prices at the beginning of the delivery month are concerned, the unbiasedness hypothesis cannot be rejected.

\section{Tests of Options Valuation}

A natural procedure for testing the validity of the option pricing model presented herein is to examine the biasedness of the model value against the observed market price; thus, for the call options, one might examine:

$$
C_{j t}(K)=\alpha+\beta V_{j t}(K)+\epsilon_{j t},
$$

where $C_{j t}(K)$ is the market price; $V_{j t}(K)$ the model value for the $K$ exercise price option $j$ at time $t$; and $\epsilon_{j t}$ is a random prediction error. A regression framework can then be used to test the null hypothesis, $H_{0}: \alpha=0, \beta=1$. Such an obvious test lacks power, however, because the (observable) intrinsic value $\max \left\{0, f_{0}-K\right\}$ is common to both $C_{j t}(K)$ and $V_{j t}(K)$ and will yield a high $\mathrm{R}^{2}$ even if the model had no ability to predict the option's time value. ${ }^{11}$ Therefore, we

\footnotetext{
${ }^{11}$ Time value is defined as the value, if any, by which the option price or value exceeds its intrinsic (premature exercise) value.
} 
subjected our model values to the more rigorous and economically meaningful test of verifying whether the model can explain the time value remaining in the call option: $c_{j t}(K) \equiv C_{j t}(K)-\max \left\{0, f_{t}-K\right\}$, where $f_{t}$ is the current market price of the futures contract at time $t$ underlying the option being valued. Similarly, computing the model's remaining time value as

$$
v_{j t}(K) \equiv V_{j t}(K)-\max \left\{0, f_{t}-K\right\},
$$

we regressed $c_{j t}$ on $v_{j t}$ (and a constant). Analogous calculations, with appropriate modifications of the maximization operator, were performed for the put options.

The regression-based tests of unbiasedness are then:

$$
\begin{aligned}
c_{j t} & =a_{0}+a_{1} v_{j t}+\epsilon_{j t}, \text { and } \\
p_{j t} & =a_{0}+a_{1} u_{j t}+\epsilon_{j t},
\end{aligned}
$$

where unbiasedness implies $a_{0}=0, a_{1}=1$. The results are presented in Table

\begin{tabular}{|c|c|c|c|c|}
\hline \multirow[b]{2}{*}{ Item } & \multicolumn{2}{|c|}{$c_{j t}=a_{0}+a_{1} v_{j t}+\epsilon_{j t}$} & \multicolumn{2}{|c|}{$p_{j t}=a_{0}+a_{1} u_{j t}+\epsilon_{j t}$} \\
\hline & All & $v_{j t}>0^{\mathrm{a}}$ & All & $u_{j t}>0^{a}$ \\
\hline $\mathrm{N}$ & 190 & 91 & 185 & 84 \\
\hline$R^{2}$ & 0.501 & 0.345 & 0.502 & 0.320 \\
\hline$\hat{a}_{o}$ & 0.0947 & 0.1566 & 0.1003 & 0.1827 \\
\hline & $(4.87)$ & $(2.32)$ & $(5.09)$ & $(3.41)$ \\
\hline$\hat{a}_{1}^{\mathrm{b}}$ & 0.9535 & $\begin{array}{r}0.8377 \\
(-130)\end{array}$ & 0.9426 & 0.7898 \\
\hline Mean $c_{j t}$ & 0.235 & 0.426 & 0.242 & 0.443 \\
\hline Mean $v_{j t}\left(u_{j t}\right)$ & 0.147 & 0.321 & 0.150 & 0.330 \\
\hline Standard $c_{i t}$ & 0.322 & 0.376 & 0.322 & 0.368 \\
\hline Standard $v_{j t}\left(u_{j t}\right)$ & 0.239 & 0.263 & 0.242 & 0.264 \\
\hline
\end{tabular}
2.

\section{TABLE 2. Comparison of Market Prices and Model Values}

Note: $\mathrm{N}=$ number of observations. Numbers in parenthesis are $t$-statistics.

${ }^{a}$ Contains only those options with strictly positive model time values.

${ }^{\text {b } T h e ~} t$-statistic is for $H_{0}: a_{1}=1$.

A comparison of the mean $c_{j t}$ and mean $v_{j t}$ values indicates that the model understates interest rate volatility relative to market prices, resulting in a downward bias of the model's call option values relative to market prices. This is attributable in part to the results of our time-series empirical tests of the perturbation functions; we found that the interest rate variables explain 66 
percent (and not 100 percent) of the subsequent shifts in the term structure of interest rates. As is well known, fitting the perturbation functions is a smoothing process, which results in the loss of some information.

Although we found that the intercept terms, $\hat{a}_{0}$, in the regressions are significantly positive, the slope coefficients, $\hat{a}_{1}$, do not differ significantly from unity. Finally, the results demonstrate that between 30 percent and 50 percent of the variation in the observed time values of the option premiums can be explained. These results are broadly supportive of the model.

\section{Trading Rule Tests}

Ultimately, any deviation between the market prices and model values must be subjected to an examination of whether such discrepancies give rise to trading opportunities.

The empirical results reported herein can be interpreted in two ways. If there are economic agents who can trade at zero-coupon bond prices, then our analysis will indicate the existence or absence of arbitrage opportunities. If the results indicate arbitrage opportunities, these can be interpreted as indicating that the model values better approximate "fair values" than do their market prices, perhaps reflecting imperfections in the market or frictions not accounted for in our tests.

To examine arbitrage opportunities in call and put option prices, we used a portfolio of three linearly independent interest-rate-contingent assets. We chose to include the futures contract as one such asset and the three-week Treasury bill, which has a known payoff, as another. Finally, we included the five-year annuity as an asset with a low correlation with the longer maturity futures and, by definition, zero correlation with the payoffs to the three-week riskless asset. At the option's expiration date in week three, the replicating portfolio should mimic the payoff to the option.

We then calculated the realized profits from a trading strategy based on the call option's current market price and the market price of the hedge portfolio. If the market price exceeds the model value for the option, the investor would short the call and buy the replicating portfolio, investing the difference in a three-week risk-free security. Conversely, if the market price is less than the model value, the investor would buy the call and short the hedge portfolio. In either case, the position would be liquidated at the option's expiration date. Analogous calculations were used in evaluating arbitrage strategies for put options.

This process was repeated for the end of January, April, July, and October in the years 1983 through 1988 whenever the shortest Treasury bond futures 
option has three weeks to expiration. Portfolios were formed for each available striking price having positive open interest and trading volume. The empirical results are reported in Table 3.

\section{TABLE 3. Analysis of Arbitrage Profits in Option Contracts}

\begin{tabular}{lrccc}
\hline \multicolumn{1}{c}{ Categories } & $\mathrm{N}$ & $\begin{array}{c}\text { Percent } \\
\text { Profitable }\end{array}$ & $\begin{array}{c}\text { Average } \\
\text { Profit } \\
\text { (\$/option) }\end{array}$ & $\begin{array}{c}t \text {-statistic } \\
\text { on Average } \\
\text { Profit }\end{array}$ \\
\hline All calls & 185 & $78.4 \%$ & $\$ 0.480$ & 1.98 \\
$c_{j t}>0$ & 163 & 75.9 & 0.555 & 2.01 \\
$c_{j t}>0, C_{j t} \geq 1 / 16$ & 115 & 68.7 & 0.770 & 1.99 \\
$c_{j t}>0, V_{j t}=0$ & 55 & 96.4 & 0.144 & 0.87 \\
$c_{j t}>0, V_{j t}=0, C_{j t} \geq 1 / 16$ & 15 & 86.7 & 0.471 & 0.77 \\
All puts & & & & \\
$p_{j t}>0$ & 179 & 79.4 & 0.545 & 2.18 \\
$p_{j t}>0, p_{j t} \geq 1 / 16$ & 173 & 79.1 & 0.563 & 2.18 \\
$p_{j t}>0, U_{j t}=0, P_{j t} \geq 1 / 16$ & 112 & 69.6 & 0.865 & 2.18 \\
\hline
\end{tabular}

Note: $\mathrm{N}=$ number of observations. $C_{j t}\left(P_{j t}\right)$ is the call (put) option's market price. $c_{j t}$ is the time value in the call (put) option's market price. $V_{j t}\left(U_{j t}\right)$ is the model's value for the call (put) option.

We thus calculated the average profit for the "all calls" and "all puts" categories as well as subcategories thereof. The choice of these subcategories was dictated by the desire to demonstrate the model's performance for options with positive time value $\left(c_{j t}>0\right.$ and $\left.p_{j t}>0\right)$, zero model value $\left(V_{j t}=U_{j t}=0\right)$, and market prices exceeding an arbitrary lower bound $\left(C_{j t} \geq 1 / 16, P_{j t} \geq 1 / 16\right)$. The empirical results demonstrate convincingly that the model values can, at least to market makers trading with close to zero transaction costs, generate arbitrage profits and therefore represent more accurately the fair value of these options. 


\section{Summary}

This analysis proposed and implemented a trinomial no-arbitrage model of state-dependent shifts in the term structure of interest rates. This model was then applied to the valuation of several important interest-dependent instruments: Treasury bond futures contracts and call and put options on these futures. The empirical results display statistically significant power in explaining the time series cross-section prices of Treasury bond futures contracts and options on these futures contracts. Further, the model appears to have some power to detect arbitrage opportunities, but only for low-transaction-cost agents able to trade at market prices and borrow/lend risklessly; alternatively, these results can be interpreted as yielding asset values closer to the arbitrage-free values of these instruments.

The model's ability to price Treasury bond futures contracts and their options successfully indicates its more general property as a mechanism for generating hedge ratios for arbitrary interest-rate-contingent claims. This nonstationary trinomial model thus constitutes important evidence on intertemporal changes in the riskless term structures of interest rates. 